\title{
STRATEGIC CONTROL LEVEL FOR INDUSTRIAL Robotic CONTACT TASKS
}

\author{
SESLIJA, D.
}

Abstract: Increasing the level of production in a flexible way with large amount of differences in lot sizes, products and order of production, became a nightmare for many of industrial engineers. Enabling automated performance of specific production cell intended for such a diverse production conditions requires a lot of research efforts. New manufacturing paradigms are being researched and developed since the last decade of the 20th century. Intelligent manufacturing systems, "holonic manufacturing system", "agent-oriented manufacturing system" and "Self Organising Complex Flexible Assembly Systems" or Bionic Assembly Systems are some of them. They were enabled thanks to the development of production systems theory that lay the ground for such paradigms. Automation is the key driver of the transformation of production for the future needs. These chapter is concerned with the development of such an automated, robotic production cell equiped with industrial robots, pneumatic and hydraulic components, sensors, PLCs and other parts of complex robotic cell. Particularly, the structure and development of the strategic hierarchical control level applied in complex robotic production cells is shown..A control structure for the robot able to assemble and machine parts in a flexible robotic cell is presented. Tasks such as deburring, grinding, engraving, cutting and assembly demonstrate appropriate contact tasks for such a cell. An expert system is proposed and several production rules are given as an example. In this chapter, efforts have been made in the direction of the development of a new generation of industrial robotic controllers with enhanced capabilities.

Key words: strategic control level, industrial robotic contact tasks, multilevel robot control, expert system
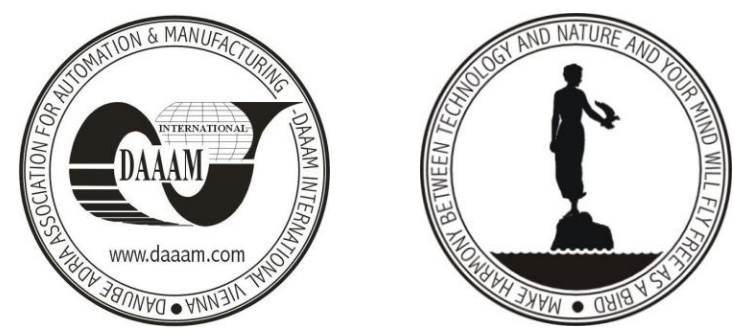

Authors' data: Prof. Šešlija, D[ragan], University of Novi Sad, Faculty of Technical Sciences, Trg Dositeja Obradovića 6, 21000 Novi Sad, Serbia, seslija@uns.ac.rs

This Publication has to be referred as: Seslija, D[ragan], (2013) Strategic Control Level for Industrial Robotic Contact Tasks, Chapter 61 in DAAAM International Scientific Book 2013, pp. 985-998, B. Katalinic \& Z. Tekic (Eds.), Published by DAAAM International, ISBN 978-3-901509-94-0, ISSN 1726-9687, Vienna, Austria DOI: $10.2507 /$ daaam.scibook.2013.61 


\section{Introduction}

The large majority of industrial engineers works at manufacturing companies, and many have specific areas of specialization, such as assembly, raw-product processing, or automation of processes. Since the core of an industrial engineer's job is the proper allocation of resources and making production processes a reality, increasing the level of production in a flexible way with large amount of differences in lot sizes, products and order of production, became a nightmare for many of them. Many research efforts are done in order to enable automated performance of specific production cell intended for such a diverse production conditions.

Some new manufacturing paradigms, which take advantage of the newest emerging mechatronics and IT technologies, and integrate them in a highly dynamic and agile technical, organizational and economic manufacturing environment, are being researched and developed since the last decade of the 20th century (Colombo, Schoop \& Neubert, 2006). They are referenced as intelligent manufacturing systems (IMS), both the "holonic manufacturing system" (HMS) and the "agent-oriented manufacturing system" and, from the other side, "SelfOrganising Complex Flexible Assembly Systems" or Bionic Assembly Systems (Katalinic \& Kordic, 2001; Katalinic et al., 2012). They were enabled, to a great extend, thanks to the development of production systems theory that lay the ground for such paradigms (Zelenovic et al., 1995; Zelenović et al., 1998; Tomović et al., 1990; Šešlija, 1988). Those paradigms have been presented in recent years as the basis for making such systems an industrial reality.

In order to realize such paradigms it is necessary to apply a high level of flexible automation. Automation is the key driver of the transformation of production for the future needs. All production activities should be a careful balance between a fixed and a flexible automation. Flexible Automation pushes for set up times reduction to enable wide mixes of components, exploiting such equipment as robots, and machining centers. The main impact refers to design (parallel layout, machining centers, Flexible Machining Systems) and the method adopted in the use phase like unmanned, centralized control (Jovaneet al., 2003). Industrial robots, AGVs, pneumatic and hydraulic components, sensors, PLCs are usual parts of complex robotic cell. The term complex robotic cell refers to robotic cells that consume any other type of energy in addition to electricity, such as compressed air, hydraulic oil, etc. (Ignjatović et al., 2013). But, today industrial robots are not useful for many necessary manufacturing tasks. Some of the reasons include complex configuration, nonintuitive (for the shop floor) programming, and difficulties instructing robots to deal with variations in their environment, etc. So, two actual challenges in order to bring to reality above mentioned paradigms, concerning industrial robots are task definitions and definition of motion control based on external sensors (Blomdell et al., 2005). Task definition is deeply connected with the purpose of robotized production cell. In this chapter is paid attention to the flexible automated production cell that uses industrial robots and other programmable equipment capable of performing various contact tasks as well as some of assembly tasks.

Manipulation requires contact with the object being manipulated or contact of manipulated object (machining tool) with the stiff environment. Robotic tasks can be classified into two categories: unconstrained and constrained motion. Unconstrained 
motion occurs when the manipulator is instantaneously free to move in any direction without contacting the environment. Examples of such tasks include spray painting and visual inspection. Constrained or contact task motion occurs when the manipulator interacts with its environment through a point or multiple points of contact (Erickson et al., 2003). Tasks such as deburring, grinding, engraving, cutting and assembly demonstrate contact tasks. Some of them are simple (like spot welding) but lots of them are rather complex (deburring or assembling). Control of such tasks could not be realized in the usual manner. Precise contact force realisation appeared to be of main importance for successful operation. This led to force control problems (Vukobratovic et al., 2001). The full potential of industrial robots can only be realized when they are applied to contact tasks.

One of the difficulties in performing contact tasks is that they require close dynamic interaction between the robot and its environment. That interaction changes the performance of the robot and can jeopardize the stability of its control system (Hogan, 1988). Compared with their robotic counterparts, humans excel at various tasks by using their ability to adaptively modulate arm impedance parameters. This ability allows human operators to successfully perform contact tasks even in uncertain environments (Kim et al., 2010). The term impedance is used here in the general sense of a dynamic relation between two variables whose inner product is power, e.g., as a generalization of the common electrical engineering term meaning a dynamic or frequency-dependent resistance (Hogan, 1988).

One of the limiting factors in the application of industrial robots for contact tasks is the capability of their control systems. Most of the commercially available industrial robots are equipped with standard control units (controllers) that are restricted to the position control. Functional constraints, as well as the limitations of computer architecture do not allow the implementation of effective control strategies based on force sensors. Modest computer capabilities, low development potential, and insufficient documentation on the controllers, hinder more significant improvements of the capabilities of industrial controllers to notice the changes in the environment that are essential for contact task execution, and act accordingly.

To overcome this problem, significant efforts have been made in the direction of the development of a new generation of robotic controllers with enhanced capabilities. In (Caccavale et al., 2005), the interaction control schemes suitable for implementation on industrial robot units are presented with the focus on impedance control and parallel control, which are conceived to manage the interaction with a more or less compliant environment without requiring an accurate model thereof. Particularly interesting direction is concerned with the problem of defining functional models and reference architectures for modern control systems (Jocković et al., 1990). Here, the emphasis is on forming a frame for integrating different complex control concepts.

Although the set of tasks requiring strong interaction with the environment is very large, the use of industrial robots on such tasks is still low due to control difficulties (Lopes \& Almeida 2008; Love \& Book, 2004; Olsson et al., 2010).

Proposed in this chapter is a concept of an advanced hierarchical control system particularly dealing with the structure of the strategic control level for the industrial robots able to deal with assembly as well as robotized machining. 


\section{Multilevel Robot Control}

The control architecture provides the instructions for creating the connections between the elements of the control system, such as the modules for task decomposition, and treatment of data obtained from sensors. There are two basic approaches to solving complex tasks of robot control: hierarchical and distributive. They do not exclude each other, i.e. certain parts within a distributive system may be organized hierarchically and vice versa.

A robotic control system usually represents a multilevel hierarchical structure with the strategic, tactical, and executive levels (Jocković et al., 1990; Katić, \& Vukobratović, 1994). In fact, these levels are based on the principle of increasing accuracy with decreasing sophistication. Within this structure, the highest level is concerned with the function of defining and planning the system tasks, whereas the lower levels (tactical and executive) carry out the control in a narrower sense. An especially good property of such control system structure is that each functional level has a distinctly and fully defined purpose of existence, which implies that the relationships between the neighboring hierarchical levels are also clearly defined.

Strategic level ensures the autonomy of robot functioning, by formulating the strategies for the preset goals. The structure of this level is presented in detail in Section 3, and here is only pointed out that the rate of operation at this level is expressed in seconds, and that this level is fully separated from lower levels, being also outside the main control cycle.

Tactical level transforms the commands related to the task level, obtained from the strategic level, into detailed commands concerning the trajectories, and forwards them to the lower, executive level. The main task of this level is, in fact, reduced to trajectory planning. At this level is also performed the mapping from the external coordinate system (the coordinate system of the robot gripper) to the joint coordinate system. The frequency of operation execution at this level is of an order of magnitude of one millisecond, ensuring thus enough time for detailed calculations.

Executive level carries out transformation of the commands defining the trajectories into the actuators responses. In principle, this is realized by using the feedback control loop on the basis of information obtained from the internal sensors at the joints, or force sensors. The rate of operation execution at this level is expressed in parts of a millisecond.

Such type of hierarchical structure ensures the basis for an open-architecture control system because the frequency range with exactly specified outputs is defined at each level. Any additional connection of the system may be categorized according to the expected effect on the outputs of the subsystems and response time of the elements to which it is attached.

Contemporary functional control architectures are usually hierarchically organized into several control levels, each of them using a variety of different control techniques. Hierarchical control is not novelty in robotics. It has been extensively used in military applications, in the domain of economics, and recently, especially in the development of Computer Integrated Manufacturing (CIM) systems. One of the first protagonists of the hierarchical structure of robotic control systems was Albus (Albus et al., 1981). Afterwards, a number of different hierarchical control concepts have been proposed (Albus et al., 1989). 


\section{Structure of the Strategic Control Level}

The strategic control level generates the goals and strategies for their attaining, the result being the realization of the overall (global) goal. At this level, the robot can generally realize the following tasks:

- $\quad$ planning of the trajectory in the presence of obstacles

- planning of forces to be exerted by the robot's end-effector (gripper/tool) on the object in the working environment

- coordination of the work of two or more robots

- optimization of the time of the robot's motion between the given positions in the space (under optimization we understand not only the trajectory minimization but also the coordination with the processes in the environment, as is the case in welding, assembling, or machining).

The above problems have received attention of many researchers, and a number of approaches assuming various models of the robot and environment, as well as the corresponding algorithms, have been proposed (Lozano-Perez et al., 1984; Katić, D. 2006).

Among the tasks allocated to the strategic level of robot control there are robotic assembly and planning of the force to be exerted by the robot gripper, as it has been presented in (Ššlija \& Vukobratović, 1998a). In the same work, a solution to the strategic control level has been proposed, primarily oriented towards solving the control problems when the time is limited, as is the case with two-hand manipulation.

In the case of the robot application in contact tasks, it is especially important to model the robot-environment system in the contact phase, as inappropriate forces (impact, the resistance force in cutting larger than the expected one, etc.) may cause damaging of either the tool, robot or the environment, workpiece or the holding tool. Also, a high-quality robot control, in the sense of effective following of the trajectory and exact realization of desired forces on the environment, is of great importance in the processes of robotized machining, as it ensures the desired quality of machining. Under quality we understand here not only the dimensional accuracy but also the quality of the processed surface - smoothness.

If we consider a flexible robotized cell for assembly and machining it can be noticed that the dynamics of the process of robotized assembly differs from the dynamics of the robotized machining. Also, in the machining processes there are a lot of differences in the dynamic behavior depending on the type of processing, sort of the material involved, and some other task characteristics.

It is obvious that one robot model and one control law cannot provide optimal solutions to the problem of robotic control in the different contact tasks. It is necessary to take into account specific features of each contact task that can be realized in the considered cell and choose the appropriate control law.

To overcome the above problems, a new solution to the strategic control level for industrial robots in contact tasks is proposed. The strategic level given in (Jocković et al., 1990) can be taken as a good basis for the synthesis of the strategic level of industrial robot control in contact tasks. As the robot movements in these tasks are relatively slow and the trajectories are mainly defined in advance, and there 
is no need for avoiding obstacles, time is not a limiting factor. So, the tasks of particular sublevels are somewhat different from those given in (Jocković et al., 1990), which is evident from Figure 1.

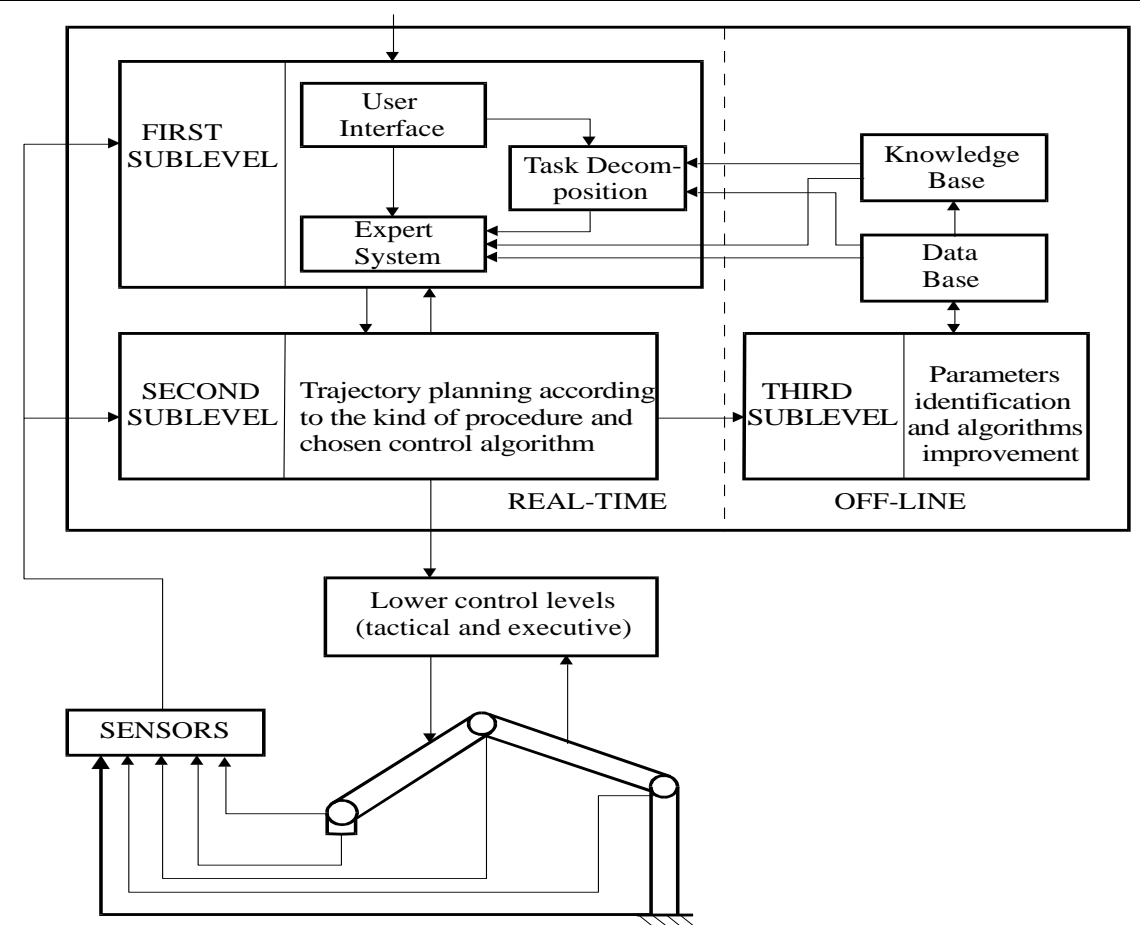

Fig. 1. Structure of the strategic control level for industrial robots in contact tasks

For choosing the appropriate robot model and control law in dependence of the type of contact task, sort of material, tool employed, etc., proposed is the use of an expert system at the strategic control level, incorporated into the first sublevel, and whose functions are:

Communication with the user, whereby either the operator or the production control level supplies data on the type of procedure (machining/assembly), kind of the process for the chosen procedure (milling, chamfering, surface cleaning, assembly, etc.), sort of material, desired trajectory, type and characteristics of the tool, and to the production control level are forwarded data about the process carried out in the cell.

Defining the robot that will carry out the operations of machining/assembly, as it is assumed that the strategic control level is of modular type.

The main function of the expert system is the choice of the appropriate control algorithms on the basis of the rules from the knowledge base and data base. It follows from the above that the expert system plays a key role in thus structured strategic control level, and the subsequent sections will be concerned with a bases for the development of such a system.

First sublevel of the strategic control level is based on the expert system that communicates with the module for communication with the user, module for task decomposition, and with the knowledge base and data base. Also, it transfers the results of its work to the second sublevel. The expert system for its operation requires the knowledge base and data base. For the functioning of the expert system it is necessary the both bases be supplied with a sufficient number of rules and amount of data.

The knowledge base, whose structure is presented in Figure 2, consists of the 
rules for choosing the appropriate control algorithms, generated on the basis of theory, simulation, and experimental research. It contains a set of rules grouped according to the process they are related to, forming thus the basis for the expert system functioning.

\begin{tabular}{|c|c|c|c|c|}
\hline Rules for assembly & \multicolumn{4}{|c|}{ Rules for machining } \\
\hline $\begin{array}{l}\text { RULE11 } \\
\text { RULE12 } \\
\text { RULE } 13\end{array}$ & $\begin{array}{l}\text { Rules for } \\
\text { machining } \\
\text { with lathe }\end{array}$ & $\begin{array}{l}\text { Rules for } \\
\text { polishing }\end{array}$ & $\begin{array}{l}\text { Rules for } \\
\text { grinding }\end{array}$ & …...... \\
\hline RULE 15 & $\begin{array}{l}\text { RULE } 21 \\
\text { RULE } 22 \\
\text { RULE } 23 \\
\text { RULE } 24\end{array}$ & $\begin{array}{l}\text { RULE } 31 \\
\text { RULE } 32 \\
\text { RULE } 33 \\
\text { RULE } 34\end{array}$ & $\begin{array}{l}\text { RULE } 41 \\
\text { RULE } 42 \\
\text { RULE } 43 \\
\text { RULE } 44\end{array}$ & \\
\hline RULE $1 \mathrm{~m}$ & RULE $2 \mathbf{n}$ & RULE 30 & RULE $4 \mathrm{p}$ & \\
\hline
\end{tabular}

Fig. 2. Structure of knowledge base for strategic control level

The data base (Figure 3) consists of several sublevels of data necessary for the functioning of the expert system: model of the environment, data on the environmental parameters, control laws, robot characteristics, characteristics of the working environment, elementary trajectories, characteristics of the technological process.

The model of the environment is important for the synthesis of force-control laws. A number of models have been proposed in the literature, starting from the simplest one (kinematic model), where the environment is simply considered as an obstacle, a constraint to motion, without taking into account its dynamic characteristics, through simple forms of the environment model of stiffness or damping type, to a general form of impedance model. Apart from these linear models of the environment, nonlinear models have been introduced, as it has been experimentally established in (Šešlija \& Vukobratović, 1998b). In addition to stiffness, it is also possible to model damping in a nonlinear form, and, of course, it is possible to have various combinations of the linear and nonlinear models (Katić, 2006). The choice of the model of the environment is not completely independent of the choice of control law. For example, in the traditional hybrid control (Raibert \& Craig, 1981) the environment is taken as a kinematic constraint, which means when this control law is chosen, a kinematic model of the environment should be associated, which is not the case with other control laws. As it has been shown in (Vukobratović \& Ekalo, 1996), such modeling is theoretically possible to apply only to the simplest cases of a planar manipulator with two degrees of freedom with translational joints, as traditional hybrid control ignores completely dynamic coupling between particular degrees of freedom, both for the position-control directions and force-control directions.

The data on the environmental parameters contain the values of the parameters of mass, damping, and stiffness, that are used in the models of the environment and are related to concrete materials that are machined in the cell, kind of the process (cutting, milling, polishing, etc.), and characteristics of the tool employed.

The data base contains a set of different control laws that can be applied for 
tasks carried out in the flexible robotized cell, and some other control laws can also be included in this base.

The software system that realizes the strategic control level is designed so that it can easily be adapted to the different manipulators. This is achieved by updating the data base segment containing data about the applied manipulator. When the existing robot is to be replaced it is necessary to enter the data about the structure of the new robot, geometric and dynamic parameters, then about the actuators parameters, and data on the end-effector employed. All the data needed for the model formation are calculated automatically and put into the corresponding bases.

Also, every new technology procedure has to be split into elementary actions and put into the base of elemental moves and activities.

The data base contains data on positions in the external coordinates for all the relevant devices and characteristic points of the environment, necessary for the cell operation. The trajectories are generated as straight lines between the defined points, and in the case the straight lines connect some points outside the robot working environment or they come across an obstacle, additional points are defined to enable its bypassing. The environment is defined by the operator in an off-line procedure in the interaction with the robot. If some changes occur within the flexible robotized cell, such as adding of some new devices, it is necessary to enter their characteristic positions into the data base.

In addition to data about the robot and positions within the cell, the data base should also contain the data concerning the technological procedure of the workpiece processing, such as the desired speed of cutting, desired forces of machining, maximal allowed deviations from the trajectory, desired surface quality, time allocated to the operation, etc.

Characteristics of a contact task are determined by the work order given by the operator, provided the robotized cell is not part of a larger automated production system, or is obtained in the frame of CIM from higher control level - the cell group control level, or directly from the control level of the production plant as a whole.

The work order arrives to the input of the block for communication with the user. The work order contains data about what is to be done, in what amount, and by what time. This module contains always information on the cell state, with three possibilities: a) Cell in work: machining the product $x x x$, scheduled finish time yyy; b) Cell free, and c) Cell in down-time state.

When a new work order has arrived, for this product and the defined technology, this module takes from the database the technological time of machining, multiplies it with the necessary number of product, and checks if the task can be realized to the scheduled time. If these conditions are fulfilled, the processing of the work order in the cell begins. The data obtained from the work order are forwarded from this module to the expert system and the module for task decomposition.

In the module for task decomposition, the data on the sort of material and machining type (i.e. on the sequence of operations in assembly processes) are decomposed into the elemental moves to be carried out by the robot, such as movements (trajectories) and activities (put on, put off, wait for some condition, etc.), and the other devices in the automated cell such as automatic screw - drivers, presses, or conveyors. This module also determines the sequence of operations. The structure of the computer program is formed as a combination of elementary operations 
programmed in advance. This is possible to realize for a predefined environment, which is the case in the industry.

Up to now, the problem of adopting the appropriate robotic control law at the strategic level in various contact-type tasks, has been mainly solved partially, for particular cases. Here, we propose the synthesis of the strategic robot control level for the different contact tasks which, using the artificial intelligence method (expert system), would make decision on the control algorithm involving contact of the robot with the environment is to be applied in the given technological procedure of machining or assembly. In this way, an attempt is made to automate generation of the control strategy for a robotized cell, capable of performing both assembly and machining.

For the development of the expert system, on the basis of theoretical considerations, a series of experiments, and simulations, it is necessary to generate the rules of the appropriate algorithm of robotic control for the tasks involving contact with the environment.

Second sublevel is concerned with the trajectory planning on the basis of the results supplied by first sublevel.

Third sublevel deals with improvement of the expert system operation on the basis of the comparison of the actual behavior of the robot with the solution given by the expert system. In the subsequent robot applications in contact tasks the obtained data can be used to model better the real robotic behavior. In this segment we envisage the use of neural networks which would be trained using the data obtained with the applied control laws and, on the basis of the training, propose the choice of the most suitable control law for the given materials, i.e. for the change of gain if necessary (Katić, 2006). Besides, here is collected the statistics on the realized technological operations (tasks) and analyzed the efficiency of the applied control laws.

In this way we completed the description of the operation of the proposed scheme of robotic control at the strategic control level in contact tasks. The next section gives several examples of the rules derived on the basis of simulation of the robot dynamics in machining processes, to provide a more straightforward explanation of how the strategic control level really works.

\section{Examples}

On the basis of the contact task type, i.e. the kind of machining/assembly, sort of the material, characteristics of the robot employed, and the characteristics of the technological procedure, the expert system should determine the appropriate control strategy and, depending on the model chosen, to carry out (if necessary) additional adjustments of the necessary parameters (e.g. adjustment of the position gain or force gain, $\mathrm{K}_{\mathrm{p}}$ or $\mathrm{K}_{\mathrm{F}}$ ).

The expert system is based on the application of production rules of the type IF... THEN..., and can, on the user's request, give explanations on the obtained conclusion (why this particular control algorithm has been chosen) by presenting the rules that have been used. For example, one of the rules is:

\section{RULE21}

IF (machining is carried out) AND 
IF (machining involves change of the material)

THEN (start machining of the most stiff material first)

EXPLANATION: Because of the impulsive change of the force when it comes to machining of a higherstiffness material in the machining involving changes of material, it is recommended that the machining begins from the end of the more stiff material.

For the given rule example there are two possible ways of activation, i.e. of obtaining the stiffness value. One is to obtain the stiffness parameter from the decomposition module together with the technology, and the other way assumes the expert system directly uses the data base and, for the obtained information on material obtains from the data base the corresponding stiffness parameters. The second variant assumes that, for the given materials the expert system data base contains data on their stiffness values.

For the development and formation of the expert system data base it is necessary to study thoroughly the existing models of robot behavior in contact tasks, their advantages, shortcomings, and limitations. In this way it is possible to generate the production rules similar to those given above, and introduce them into the knowledge base of the expert system. This is actually the most difficult part in forming the expert system; it is most time-consuming as for obtaining only one rule it is often necessary to carry out a number of extensive experiments or simulations. Here is presented several more rules with the aim to explain better the way of functioning of the proposed strategic level of robotic control in contact tasks. By the above rule (rule No. 21), only the approaching trajectory and the direction of machining have been determined. The following rules serve to choose the control law.

\section{RULE22}

IF (machining is carried out) AND

IF (machining involves change of the material)

THEN (apply control law (2))

EXPLANATION: In the material processing by cutting, such as leveling of the joint of two materials, it is essential to have the exact workpiece dimensions, so that is recommended to use the control law predominantly involving position-control, as defined by the expression (2) from the data base given in Fig. 3.

After being chosen in this way, the control law is forwarded to lower control level for realization. However, the knowledge base contains the following rule:

\section{RULE23}

IF (machining is carried out) AND

IF (machining involves milling) AND

IF (aluminum is machined)

THEN (it is not possible to apply control law (2))

EXPLANATION: On the basis of the simulation results for the robot dynamic behavior in milling, it has been established that in aluminum machining using control law (2), higher stiffness values cause this control law be incapable of controlling effectively the penetration force at the desired level, as this force can have very large oscillations, with maximum values exceeding even 80 N (Šešlija \& Vukobratović, 1998b).

If one of the machined materials is aluminum, and the machining involved is milling, than the rules 22 and 23 conflict with each other. For resolving such conflicting situations it is necessary to propose some new rules. The possibilities are either to change the technology and carry out machining by cutting (if there are possibilities for this), or, to apply a control law stabilizing dominantly force (as is the 


\begin{tabular}{|c|c|c|c|c|c|c|c|}
\hline \multicolumn{2}{|c|}{\begin{tabular}{|c|c|c|c|} 
Ervironment Models \\
\end{tabular}} & \multicolumn{3}{|c|}{ Erviromutent Paumeters } & \multirow{2}{*}{\begin{tabular}{|c|} 
Fechodogical \\
pioocture
\end{tabular}} & \multirow{2}{*}{$\begin{array}{c}\text { Robot } \\
\text { dah }\end{array}$} & \multirow{2}{*}{$\begin{array}{l}\text { Work } \\
\text { speoce }\end{array}$} \\
\hline \multirow{2}{*}{ 弟 } & $\mathrm{x}=\phi(q)$ & & Stiffiess & Dermpirg & & & \\
\hline & $\phi(q)=0$ & . & $\begin{array}{l}\text { ariminum } \\
\text { stoel } \\
\text { wood }\end{array}$ & $\begin{array}{l}\text { ahminum } \\
\text { stoel } \\
\text { wood }\end{array}$ & \multirow{3}{*}{ 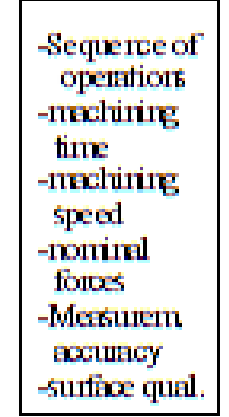 } & \multirow{3}{*}{ 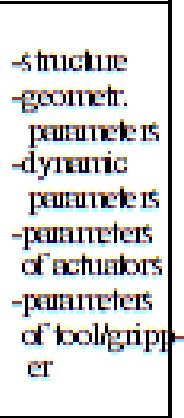 } & \multirow{3}{*}{$\begin{array}{l}\text { positions: } \\
\text { for gres ping } \\
\text { for dioping } \\
\text { for staut of } \\
\text { machining } \\
\text { for puess } \\
\text { for vbrator } \\
\text { for staut of } \\
\text { cssenbly }\end{array}$} \\
\hline \multirow{2}{*}{ 光 } & 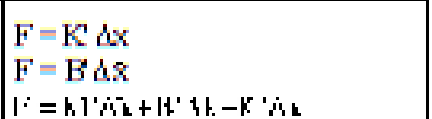 & 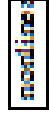 & $\begin{array}{l}\text { ahumuium } \\
\text { stoel } \\
\text { xood }\end{array}$ & $\begin{array}{l}\text { ahuinum } \\
\text { stoel } \\
\text { wood }\end{array}$ & & & \\
\hline & 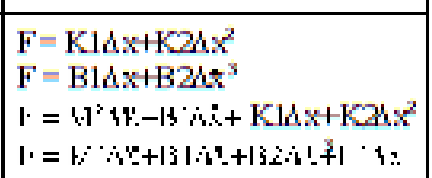 & \multicolumn{2}{|c|}{\begin{tabular}{|l|} 
Iool pickug \\
Iool replaoenent \\
Put aside \\
Assenble \\
\end{tabular}} & $\begin{array}{l}\text { Workpeo appr- } \\
\text { och } \\
\text { Machuring } \\
\text { Iool bese poxit. }\end{array}$ & & & \\
\hline \multicolumn{8}{|c|}{ Conthol laxs } \\
\hline \multicolumn{4}{|c|}{ 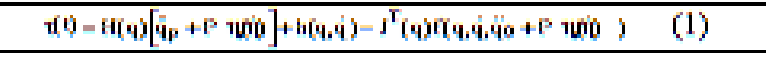 } & \multicolumn{4}{|c|}{$\left.\eta(0)=J^{\top}(4)+x^{\prime} d \alpha+\theta^{\prime} d x+K^{\prime} d x\right)-F(x)+H^{\prime}(4,4) \quad(3)$} \\
\hline \multicolumn{4}{|c|}{ 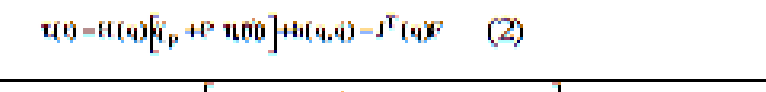 } & $\mathrm{u}(0)=\mathrm{H}(\varphi) \mathrm{M}^{-1}(\mathrm{\varphi})$ & \multicolumn{3}{|c|}{ 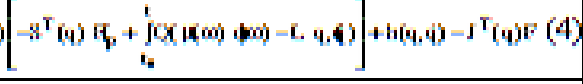 } \\
\hline \multicolumn{5}{|c|}{ 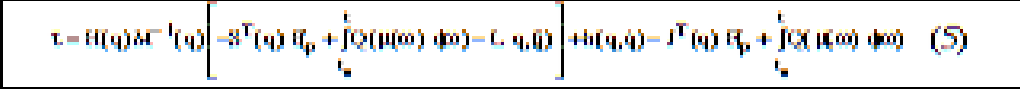 } & & & \\
\hline \multicolumn{8}{|c|}{ 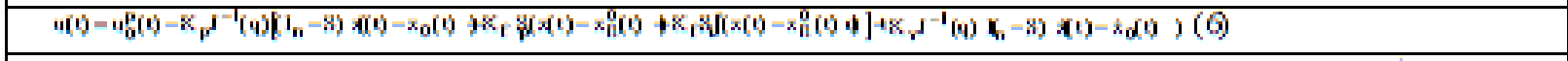 } \\
\hline \multicolumn{8}{|c|}{ 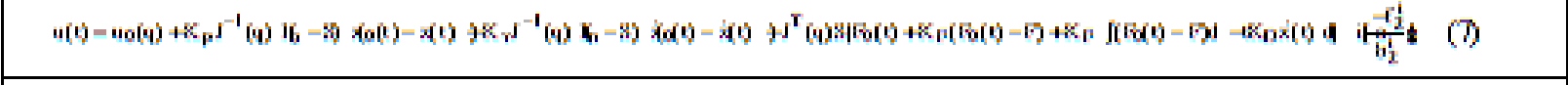 } \\
\hline \multicolumn{8}{|c|}{ 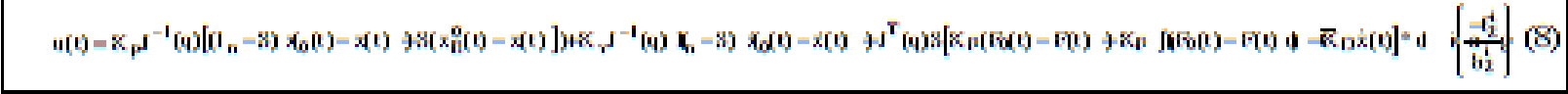 } \\
\hline
\end{tabular}

Fig. 3. Structure of the data base for the strategic control level

case with the control law given by expression (5)), but in this case it is necessary to introduce some additional rules. The presented examples clearly illustrates what are the problems to be solved by the designer of an expert system for the strategic level of industrial robot control in contact tasks.

\section{Conclusion}

In this article is proposed a hierarchical concept of robotic control in contact tasks. For a flexible robotized cell we propose the control structure with three main levels (strategic, tactical, and executive), special attention being paid to the strategic level. Proposed is the introduction of "intelligent" control using methods of artificial intelligence. Three sublevels are proposed for this strategic level, and a key part of the first sublevel is an expert system for the determining of the control law. Besides, the modules for task decomposition, as well as the second sublevel of the strategic control level, which is concerned with trajectory planning and supervising of the execution of the task as a whole, play, also, a significant role. Several examples of production rules, generated on the basis of the robot dynamics simulation in particular contact tasks, are given. Method proposed in this chapter optimizes the performance of the contact tasks in uncertain or changeable conditions of the environment.

Further studies should:

- $\quad$ explore deeply the real forces acting between different tools and different materials during robotic contact tasks, 
- $\quad$ adequately model the robot control parameters in order to better complain with particular environment characteristics and

- $\quad$ find more adequate rules for particular cases of robotic contact tasks in order to better bring in practice envisioned strategic control level.

Further studies should, also, take into account the problem of robot motion in a free space (contact-free motion), and especially the phase of the occurrence of contact (i.e. impact) with the workpiece surface. This is a special research problem requiring deeper studies. In addition to the problem of machining in a flexible cell, assembly of parts represents also a wide research field.

These chapter proposes only a concept of the strategic control level and discusses only in general the structure of each level. In the further work it will be necessary to work out in detail both the input and output formats, as it has been proposed in (Albus, McGain, \& Lumia, 1989) and to embed other known principles of industrial engineering mostly linked to sustainable production like improving energy and material efficiency into the highest level of strategic control.

Besides well known principles of reducing electric energy, potentially very fruitful avenues for further research is to ensure good energy efficiency of other energy sources in robotic production cell like hydraulic energy or compressed air energy. As it is shown in (Ignjatović, Komenda, Šešlija, \& Mališa, 2013), there is a lot of tricky questions related to the sequence and techniques of energy optimization in robotic production cell. Also, due attention should be paid to reusing of compressed air (Blagojević, Šešlija, \& Stojiljković, 2011; Blagojević, Šešlija, Stojiljković, \& Dudić, 2013) in pneumatic part of complex robotic cell and leakage reduction (Dudić, Ignjatović, Šešlija, Blagojević, \& Stojiljković, 2012). Material efficiency should also be accounted for because for the most materials used to provide buildings, infrastructure, equipment and products, global stocks are still sufficient to meet anticipated demand, but the environmental impacts of materials production and processing, particularly those related to energy, are rapidly becoming critical (Allwood, Ashby, Gutowski, \& Worrell, 2011). Having in mind those principles and techniques interesting problem will be to create and embed in strategic control level appropriate rules for adequate control of processes in robotic production cell. Concerning all the mentioned issues, several conclusions regarding refocusing of time and energy for improving industrial engineering higher education can be drawn. In future curriculum development for industrial engineering and in practical realization, especially on master and Ph.D. level, following should be obeyed:

- insistence on applying systematic approach in developing new solutions for production problems as well as for solving problems in operation of factories,

- developing conceptual thinking of students with taking in account multiple sides of concerned problems,

- not focusing on pure data rather on putting data in appropriate contextin order to draw conclusions useful for the control of processes.

\section{References}

Albus, J. S., Barbera, A. J., Nagel, R. N., (1981). Theory and Practice of Hierarchical 
Control, 23rd IEEE Computer Society International Conference, 18-27

Albus, J. S., McGain, H. G., Lumia, R., (1989). NASA/NBS Standard Reference Model for Telerobot Control System Architecture (NASREM), NIST Technical Note 1235, National Institute for Standards and Technology, Gaithersburg

Allwood, J. M., Ashby, M. F., Gutowski, T. G., \& Worrell, E. (2011). Material efficiency: a white paper. Resources, Conservation and Recycling, 55(3), 362-381 Blagojević, V., Šešlija, D., \& Stojiljković, M. (2011). Cost effectiveness of restoring energy in execution part of pneumatic system. Journal of Scientific and Industrial Research, 70(2), 170-176

Blagojević, V., Šešlija, D., Stojiljković, M., \& Dudić, S. (2013). Efficient control of servo pneumatic actuator system utilizing by-pass valve and digital sliding mode. Sadhana, 1-11

Blomdell, A., Bolmsjo, G., Brogardh, T., Cederberg, P., Isaksson, M., Johansson, R. \& Wang, J. (2005). Extending an industrial robot controller: implementation and applications of a fast open sensor interface. Robotics \& Automation Magazine, IEEE, 12(3), 85-94

Caccavale, F., Natale, C., Siciliano, B., \& Villani, L. (2005). Integration for the next generation: embedding force control into industrial robots. Robotics \& Automation Magazine, IEEE, 12(3), 53-64

Colombo, A. W., Schoop, R., \& Neubert, R. (2006). An agent-based intelligent control platform for industrial holonic manufacturing systems. Industrial Electronics, IEEE Transactions on, 53(1), 322-337.

Dudić, S., Ignjatović, I., Sešlija, D., Blagojević, V., \& Stojiljković, M. (2012). Leakage quantification of compressed air using ultrasound and infrared thermography. Measurement, 45(7), 1689-1694

Dudić, S., Ignjatović, I., Šešlija, D., Blagojević, V., \& Stojiljković, M. (2012). Leakage quantification of compressed air on pipes using thermovision. Thermal Science, 16(suppl. 2), 555-565

Erickson, D., Weber, M., \& Sharf, I. (2003). Contact stiffness and damping estimation for robotic systems. The International Journal of Robotics Research, 22(1), 41-57

Hogan, N. (1988). On the stability of manipulators performing contact tasks. Robotics and Automation, IEEE Journal of, 4(6), 677-686

Ignjatović, I., Komenda, T., Sešlija, D., \& Mališa, V. (2013). Optimisation of compressed air and electricity consumption in a complex robotic cell. Robotics and Computer-Integrated Manufacturing, 29(4), 70-76

Jocković, M., Vukobratović, M., \& Ognjanović, Z. (1990). An approach to the modeling of the highest control level of flexible manufacturing cell. Robotica, 8(02), $125-130$

Jovane, F., Koren, Y., \& Boer, C. R. (2003). Present and future of flexible automation: towards new paradigms. CIRP Annals-Manufacturing Technology, 52(2), 543-560

Katalinic, B., \& Kordic, V. (2001). Concept of Design and Scheduling of SelfOrganising Complex Flexible Assembly System. In Proceedings of 10 th International Conference on Flexible Automation and Intelligent Manufacturing, Zhang, G.(Ed.) 215-223

Katalinic, B., Pryanichnikov, V. E., Ueda, K., Cesarec, P., Kukushkin, I., \& Kettler, R. (2012). Bionic Assembly System: working modes, control and scheduling. 
International Journal of Industrial Engineering and Management,3(3), 121-131

Katić, D., \& Vukobratović, M. (1994). Connectionist approaches to the control of manipulation robots at the executive hierarchical level: An overview. Journal of Intelligent and Robotic Systems, 10(1), 1-36

Katić, D. (2006). Advanced Connectionist Control Algorithm for Robotic Compliance Tasks based on Wavelet Network Classifier. Scientific Technical Review, 56(2), 24-29

Kim, B., Park, J., Park, S., \& Kang, S. (2010). Impedance learning for robotic contact tasks using natural actor-critic algorithm. Systems, Man, and Cybernetics, Part B: Cybernetics, IEEE Transactions on, 40(2), 433-443

Lopes, A., \& Almeida, F. (2008). A force-impedance controlled industrial robot using an active robotic auxiliary device. Robotics and Computer-Integrated Manufacturing, 24(3), 299-309

Love, L. J., \& Book, W. J. (2004). Force reflecting teleoperation with adaptive impedance control. Systems, Man, and Cybernetics, Part B: Cybernetics, IEEE Transactions on, 34(1), 159-165

Lozano-Perez, T., Mason, M. T., \& Taylor, R. H. (1984). Automatic synthesis of fine-motion strategies for robots. The International Journal of Robotics Research, 3(1), 3-24

Olsson, T., Haage, M., Kihlman, H., Johansson, R., Nilsson, K., Robertsson, A., ... \& Brogårdh, T. (2010). Cost-efficient drilling using industrial robots with highbandwidth force feedback. Robotics and Computer-Integrated Manufacturing, 26(1), 24-38

Raibert, M. R, and Craig, JJ., (1981)." Hybrid Position/Force Control of Manipulators, Trans. of ASME, Journal of Dynamic Systems.Measurement and Control ('v1D3, n2), 126-I33

Šešlija, D. (1988). Industrial Robot Programming in Assembly Using GT Approach. Strojarstvo, 30(5/6), 243-247

Šešlija, D., \& Vukobratović, M., (1998a). On the strategical control level for robotic contact tasks, In Proc. of Fourth ECPD Intern. Conf. on Advanced Robotics, Intelligent Automation and Active Systems, Moscow, Russia, 256-263

Šešlija, D., Vukobratović, M: (1998b). On the environment dynamics parameters in robotic contact tasks, part 1: Identification of forces, stiffness and damping; Int. Jour. of Engineering and Automation, No 4, Moscow, Russia, 26-44

Tomović, R., Zelenović, D., \& Šešlija, D. (1990). The role of intelligent robots in flexible assembly. Computers in Industry, 15(1), 131-139

Vukobratović, M. K., \& Ekalo, Y. (1996). New approach to control of robotic manipulators interacting with dynamic environment. Robotica, 14(01), 31-39

Vukobratovic, M., Potkonjak, V., \& Matijevic, V. (2001). Contribution to the study of dynamics and dynamic control of robots interacting with dynamic environment. Robotica, 19(02), 149-161

Zelenović, D., Burbidge, L. J., Ćosić, I., \& Maksimović, R. (1995). The division of large complex production systems, into independent, autonomous units. In Proceeding of 13th International Conference of Production Research, ICPR, Global Frontiers in Manufacturing, 213-215

Zelenović, D., Ćosić, I., \& Maksimović, R. (1998). Design and reengineering of production systems: Yugoslavian (IISE) approaches. In Group Technology and Cellular Manufacturing, Springer US, 517-536 